\title{
Lexis
}

Journal in English Lexicology

$8 \mid 2014$

Metaphor Studies in the English Language

\section{Rare, obscure and marginal affixes in English}

\section{Laurie Bauer}

\section{(2) OpenEdition}

\section{Journals}

Electronic version

URL: http://journals.openedition.org/lexis/304

DOI: $10.4000 /$ lexis.304

ISSN: 1951-6215

\section{Publisher}

Université Jean Moulin - Lyon 3

\section{Electronic reference}

Laurie Bauer, «Rare, obscure and marginal affixes in English », Lexis [Online], 8| 2014, Online since 09 January 2014, connection on 30 April 2019. URL : http://journals.openedition.org/lexis/304 ; DOI : 10.4000/lexis.304

This text was automatically generated on 30 April 2019.

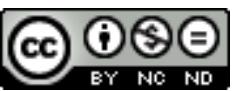

Lexis is licensed under a Creative Commons Attribution-NonCommercial-NoDerivatives 4.0 International License. 


\title{
Rare, obscure and marginal affixes in English
}

\author{
Laurie Bauer
}

\section{Introduction}

1 English is rich in derivational morphology, though relatively poor in inflectional morphology. English derivational morphology has been described in a number of handbooks, but perhaps most notably in Marchand [1969]. Just where the borderline between things that are part of the morphology of English (albeit not the productive morphology of English) and historical randomness of form should be drawn is not always clear. Marchand himself lists a number of affixes which few other authorities on English mention as affixes (see below for examples). In this paper I list and discuss some of these marginal cases on both sides of the divide between morphology and non-morphology.

2 Two features are expected of affixes. The first is that they should be recurrent with a fixed meaning. It follows that affixes which can be analysed in very few words are potentially controversial. There can be no absolute answer to how many 'very few' might be, and examples listed below vary from just one word to instances where there are relatively many, but only in restricted domains. The second feature of affixes is that we expect them, other things being equal, to be parallel to similar affixes. Part of the reason that we feel justified in analyzing -ter in laughter is that there are affixes which have similar function in words such as admittance, conjecture, enjoyment, rejection and so on, all of which may glossed as 'the action of VERB-ing'. The fact that laughter has undergone semantic change so that it can also denote a sound is not unusual in such nominalizations: the word admittance can also denote a sum of money, for instance.

3 Controversial affixes, or marginal affixes, thus typically are rare, or do not have a fixed meaning, or do not have other parallel affixes. When all these factors align, we usually decide that there is no morphology. It is much more difficult to decide what is going on when there has been morphology, but that morphology is no longer productive. In such instances, the affix is often no longer analyzable for current speakers. An example might 
be the -le which occurs in words like sparkle and twinkle (and an indefinite number of other forms) which may be recognizable for the etymologist but not for the modern speaker of English. Productivity does not necessarily make matters any clearer. Blends may be productive as well as affixes, and some forms may be productive because they occur as splinters in blends. The borderline between a splinter and an affix may not be clear: -scape started off as a splinter from landscape, but whether moonscape is a blend of moon and landscape or the affixation of -scape to moon is impossible to determine without some artificially precise definition of the difference.

\section{Some relevant affixes}

\subsection{The prefix pel-}

4 The initial <pel> in pellucid is, etymologically speaking, a variant on Latin per-, but pellucid is the only place in which this form has persisted into English. Since the meaning of pellucid is clearly related to that of lucid, it seems we must recognize a prefix here, albeit a unique one.

\subsection{The prefix preter-}

5 There is no doubt as to the prefixal value of preter-in preternatural. And preter- does occur in other combinations, too: preter-Christian, preter-diplomatic, preternative, preternuptial are listed in the $O E D$, for example. However, it is a rare prefix, its functions usually being taken by extra- or ultra-.

\subsection{The prefix twi-}

6 Marchand [1969: 200] mentions this prefix, whose use in contemporary English is virtually restricted to the word twilight. In that particular combination its original meaning of 'two' is not recuperable. In twibill ('a two-headed axe') or twichild ('a person in second childhood') the meaning is more transparent, but the words are extremely rare.

\subsection{The suffix -ard $]_{N}$}

7 There are a handful of words left in which -ard is analyzable, including dotard, drunkard, laggard, sluggard, and the words are no longer frequent. Marchand [1969: 252] suggests that the suffix has not been productive since the $17^{\text {th }}$ century. Other words containing the suffix, from a historical point of view, are bastard, buzzard, coward, wizard. Marchand gives the form braggart as showing an alternative spelling of the same suffix.

\subsection{The suffix -ard $]_{v}$}

The word bombard may be the only verb with a clearly semantically related base ending in -ard. Historically it arises as part of the same set of stress-shifting words as export and expórt from an earlier noun bómbard (OED, where it is also noted that there is no etymological relationship with bomb). So we have here a double chance that makes bombard look like a derived verb: the loss of the noun bombard, and the falling together of 
the first syllable with the word bomb. There is no historical affixation, it only looks from our present viewpoint as though there might have been.

\subsection{The suffix -art}

9 For the suffix -art as in braggart see the section on -ard $]_{\mathrm{N}}$.

\subsection{The suffix $-c$}

10 Part of the problem with this suffix is determining its form. In words ending in -ia, it has the form -c, as in maniac; in words where it is added to a bound base, it has the form -iac, as in aphrodisiac. It is also difficult to determine just which words contain the affix, which does not seem to be productive. A relatively complete list of candidates is given in (1), though some of these words have derivatives, as well. Some of these words are adjectives, some nouns, some both.

(1) ammoniac, aphasiac, aphrodisiac, c(o)eliac, cardiac, demoniac, elegiac, $h$

(a)emophiliac, hypochondriac, iliac, insomniac, maniac, melancholiac.

11 Words such as celeriac, salmiac, zodiac which end in the same sequence are probably monomorphemic, but it is difficult to be sure, partly because the contribution of the suffix is so difficult to determine. Etymologically, salmiac is a shortening of sal ammoniac (though not an English shortening), the -iac in zodiac has the same origins as those listed in (1), and the -ac in celeriac is unexplained (OED). The most clearly suffixed of the forms in (1) are those where the suffix can be given the reading 'person suffering from $\sim$ '. It might also be possible to propose a homophonous adjective-forming suffix. The small number of examples, the difficulty in deciding which words carry the suffix or suffixes and its lack of productivity make it extremely marginal in English. The relatively new form brainiac is almost certainly a blend of brain and maniac, not a new $-c$ formation.

\subsection{The suffix -ee}

12 There is a productive suffix -ee which may be seen in established words like absentee, employee, lendee, but there are also words which appear to have a different suffix -ee, or, indeed, a number of different suffixes.

13 The -ee on bootee was once part of a wider series of clothing -ee words, including coatee and shirtee (Marchand [1969: 268]), and these could all be respellings (and restressings) of the diminutive -ie suffix found in tootsie. The suffix on bargee does not imply any of the lack of volition that is associated with the productive -ee (Barker REF). Perhaps this is again a reformulation of the diminutive -ie suffix in words like goalie and roadie. Townee ('person from the town rather than from the university') could have a similar origin.

14 Settee could be related to set (compare settle for a similar piece of furniture). There is no particular reason to expect it to be diminutive, although diminutives can occur almost anywhere in unexpected places. Although, like words derived with the productive -ee, it can be read as being a patient noun ('a thing on which a person is set/sat'), productive -ee words are, if not technical, human, which settee is not. 


\subsection{The suffix -(e)rel}

15 A few words in -(e)rel appear to be English formations, extending the pattern of unanalysable French models (kestrel, mackerel). The two strongest examples of the type are cockerel and mongrel (the latter no longer analyzable as coming from a verb meaning 'mix', compare among). Scoundrel may be another example, wastrel probably is, and Scottish English gomerel 'foolish person' (variously spelt) may be another. Pickerel 'a young or small sp. of pike' is a fairly technical fishing term.

\subsection{The suffix -ine}

The suffix -ine (sometimes spelt -ene) derives from female names like Geraldine, Pauline, and is found on a word which appears to have had a rather short life - leaderene, as applied to Margaret Thatcher. There are alternative uses of -ine and -ene, the former as an adjectival suffix, the latter in technical chemical names, but they are separate forms.

The homophonous -een is analyzable in very few words in English, and those are rare. Girleen and squireen are listed in the OED. It is apparently an Irish diminutive suffix, and can be found etymologically (though it is no longer analyzable in English) in the words colleen and poteen.

\subsection{The suffix -lin}

18 The suffix -lin found in dunlin 'bird sp' is apparently a variant of the much more usual ling suffix. It may be the only current word to contain this variant.

\subsection{The suffix -mo}

19 Marchand [1969: 333] mentions this affix as coming from printers' slang. It originates from a Latin model illustrated by duodecimo, which gave English twelvemo (often written $12 \mathrm{mo}$ ), meaning a sheet of paper folded to give twelve pages. The numbers used are limited by the possibilities of folding paper and the requirements of the printing industry, so the productivity of the affix was never great, and its domain of usage always extremely restricted.

\subsection{The suffix -ern}

There are a number of words which end in -ern (including bittern, lantern, pastern, pattern, tavern, wyvern), only in cavern does it seem possible to see it as having morphemic value. The OED sees the same suffix as in eastern etc, but that creates adjectives, while cavern is a noun. The strange thing about -ern as a suffix is that it appears to mark an augmentative, though English does not have any productive augmentative suffixes. The OED says that " cavern is vaguer and more rhetorical [than cave], usually with associations of vastness". It is the spelling and the meaning which leads to the conclusion that this must be an isolated affix, despite the vowel change from /eI/ to /æ/ in an unpredictable environment. 


\subsection{The suffix -ice}

21 There are sufficient words with -ice analyzable as a nominalization marker to justify calling this a suffix: cowardice, justice, notice, service. However, there are not very many such words, the form does not appear to be productive, and there are even more words where the presence of the same affix is questionable or unlikely: bodice, licorice, mortice (more usually spelt <mortise>), office, practice, solstice, in none of which the OED finds a suffix, though it notes that the second $\langle\mathrm{c}>$ in practice may have been influenced by the suffix.

\subsection{The suffix -ock}

In most words where the final sequence <ock> occurs it is difficult to see any morphological value for the sequence. Such words include buttock, haddock, hassock, mattock and tussock. In a handful of words, however, it can be analyzed as attaching to a root and being meaningful in relation to that root. For instance hillock denotes a small hill and bullock a young bull, and in both cases there is a diminutive relation between the base and the potentially suffixed form. In some other words, any such relationship is less clear: ballock (more usually spelt <bollock>) and pillock would fit (depending on the meaning attributed to pillock: according to the OED it originally meant 'penis', but today bollocks and pillocks can be used synonymously to mean 'nonsense', and pills can be used to mean 'testicles'); dunnock might or might not fit - it denotes a small, dun-coloured bird, the hedge-sparrow.

\subsection{The suffix -red}

The suffix -red that we find in hatred is an affix corresponding to a free form in earlier Germanic, and semantically related to forms like -head, -hood. What is etymologically the same suffix occurs in kindred, but the identity is masked by the excrescent $<\mathrm{d}>$ in kindred. Other words with this suffix appear to have died out, so that hatred now remains in isolation.

\subsection{The suffix -ric}

The suffix -ric is cognate with the German word Reich 'empire' and, like several other abstract-noun forming affixes in English, is an instance of a suffix being derived historically from a free noun. Today it is left only in bishopric and archbishopric. Other words with the same suffix, some formed independently of bishopric, others apparently formed on the basis of bishopric, have not survived (OED), though it is not clear why this should be.

\subsection{The suffix $-t$}

There is a nominalization suffix of form - $t$ which can be found in a number of words, including complaint, constraint, draught, flight, onslaught, restraint, sight, thought. From an etymological point of view, there are two suffixes here, one derived from French and the other from Germanic. The Germanic suffix is a variant of the -th suffix we find with words 
such as health, length, truth. It also occurs in the form -t on the end of an adjective in height . In modern English, final $-t$ and final $-t h$ are not perceived as variants of the same affix.

\subsection{The suffix -ter} could have been the basis for other words adopting the sequence -ola, particularly if the diminutive force of the words in (2) was not recognized. There are a few words where, -ola seems to be used with augmentative force rather than diminutive. There are not many of these, but the fact that the same sequence can have apparently conflicting meanings is worrisome. Relevant words are problemola and possibly crapola (although the latter could be a collective rather than an augmentative).

Each has given rise to a host of nonce-for to few permanent inhabitants of dictionaries. Both appear to be more familiar in North American than in British English. Even here, the two have contrasting meanings, the -ola 
in payola apparently being extremely disparaging, while that in granola is at least intended as being very positive. Whether the -ola in Shinola (once a trade name, now mainly in the North American English expression not to know the difference between shit and Shinola) produces yet another meaning of -ola is not clear.

There is certainly a claim to be made for the suffixal status of -ola, though how many homophonous suffixes should be analyzed is far less clear. It seems likely that in origin the formative -ola was not morphological but merely decorative, which made its usage in trade names seem safe. But as we see with other names such as nylon, Dacron, rayon, etc., if too many semantically related words with a similar form are coined, the form starts to appear meaningful.

\subsection{The possible suffix -ose}

According to the OED, the suffix -ose is a variant of -ous, often reformed on a Latin basis. It can be found in English in a few places where it is analysable, as in comatose, globose, verbose, and rather more often in places where it would have to be considered to be attached to a bound base: jocose, morose and a few scientific terms. It does not carry any particular meaning beyond being adjective-forming. While the OED lists plenty of forms which could be interpreted as carrying this affix, they are mostly scientific forms and unfamiliar to most speakers. There are sufficient forms to recognise an affix here, but it is not much found in non-specialized words.

\section{Non-affixal morphology}

There are a few pairs of words which are related by apophony, which seems to be the remnant of an earlier Germanic form of word-formation, although few speakers of modern English will have much reason to see anything but chance resemblance between words here. The first set are causative verbs, as illustrated below.

\begin{tabular}{|l|l|l|l|}
\hline (3) & sit & & set \\
\hline & lie & & lay \\
\hline & fall & & fell \\
\hline & rise & & raise \\
\hline
\end{tabular}

The second set is made up of noun-verb pairs, and they are listed below.

\begin{tabular}{|l|l|l|l|}
\hline (4) & abide & & abode \\
\hline & bind & & band \\
\hline & bleed & & blood \\
\hline & drip & & drop \\
\hline
\end{tabular}




\begin{tabular}{|c|c|}
\hline feed & food \\
\hline sell & sale \\
\hline shoot & shot \\
\hline sing & song \\
\hline sit & seat \\
\hline stroke & strike \\
\hline
\end{tabular}

\section{Some irrelevant forms}

In this section we consider some forms which look as though they might have morphemic value, but which are too marginal to be considered morphological. Their marginality is largely due to their not being parallel affixes with similar functions, so that they have to be seen as phonological coincidences, whatever their origins may be.

\subsection{The non-prefix c-}

In the game or croquet, a roquet shot is the shot a player makes when approaching a ball, and the croquet shot is the shot the player makes when moving away from the ball: the croquet shot is thus typically the shot played immediately after the roquet shot. The form croquet contains roquet, and it looks as though the two should be related. The OED is puzzled by the relationship between the two words, and it is not entirely clear what meaning would have to be attributed to the putative $c$ - prefix. The lack of meaning and the lack of parallel prefixes suggest that the relationship between roquet and croquet cannot be considered a morphological one.

\subsection{The non-prefix c-}

There is another apparent unique morph $c$ - which arises in covert. These days, covert is pronounced with an /əo/ in the initial syllable, because of constant collocation with overt , and this makes it look as though there could be a negative morpheme with the form $c$-. Historically, though covert is linked to cover, and the OED still lists a pronunciation with / $\Lambda /$ in the initial syllable, while overt is linked to French ouvrir 'to open'. So historically there is no prefix here. Today, it would seem there is more reason to perceive one, but since $c$ - does not recur with negative meaning, there is little to be gained by an analysis of this as a prefix.

\subsection{The non-prefix $h$ -}

Various writers have noted that the relationship between ear and hear does not lead to a word *heye meaning 'to perceive with the eye' (*hnose and *htongue would be phonologically impossible). The OED says that it is unlikely there is any relation between 
ear and hear etymologically, and morphologically the lack of any parallels suggests that there is no synchronic relation either.

\subsection{The non-prefix $u$ -}

41 Given the existence of dystopia, it might be expected that there is a bound base -topia to which the prefix dys- has been added. However, that implies a prefix $u$-in utopia, possibly on the assumption that the prefix is eu- as in euphemism, euphony. However, etymologically speaking, dystopia must be seen as a blend of dysfunction (or other word beginning with dys-) and utopia.

\subsection{The non-suffix -ish $]_{v}$}

While the syllable $[\mathrm{I}]]$ is frequently found at the ends of verbs, there is no evidence that it is a suffix in English. Relevant words include admonish, astonish, brandish, cherish, diminish, distinguish, establish, extinguish, finish, flourish, impoverish, nourish, polish, publish, relish, tarnish, vanquish, varnish. Of these, the most likely word to have a suffix is probably publish , where there is an apparently corresponding bound root already in public. Brandish and flourish do not have enough meaning in common to motivate an affix.

\subsection{The non-suffix -oon}

In a few words we find an apparently separable sequence -oon, as in balloon, doubloon, spittoon. There are many other words, however, where the same sequence does not appear to be analyzable: these include cartoon, festoon, harpoon, pantaloon, platoon, poltroon. These have various sources in the Romance languages, sometimes, but not always, as an affix. Moreover, even in the words where it appears analyzable in English, it does not appear to have any fixed meaning. It thus seems that there is not sufficient evidence to call -oon a suffix in current English.

\section{Conclusion}

It might seem that the argument here is about a few left-overs from the word-formation system of English, and a very few items which were never part of the word-formation system of English, but might appear to have been so. And, in large part, that is so. However, some of the forms listed here appear to be productive. The most obvious of these is -ola. The odd thing about -ola is that it seems to break one of the most fundamental tenets about productive morphology: Aronoff [1976: 39], citing Zimmer [1964: 32] points out that we should expect to know what a productively produced form will mean. With -ola (which can apparently be a diminutive, an augmentative, a pejorative or an ameliorative, not always in a way which is predictable from the base) we may not meet the demand that "the surer one is of what a word will mean, the more likely one is to use it" [Aronoff 1976: 39].

It seems unlikely that the list of marginal forms I have given here is exhaustive. Forms like the $c$ - in covert, the $u$-in utopia are hard to find, but are probably more widespread than this article would indicate. Potentially, they could become key words which 
restructure parts of English morphology, but this seems unlikely. However, any system in which a foreign prefix like über- can suddenly invade an area in which there are several competing prefixes (super-, mega-, over-, etc), perhaps nothing can be ruled out.

\section{BIBLIOGRAPHY}

ARONOFF Mark, Word formation in generative grammar, Cambridge, MA: MIT Press, 1976.

BARKER Chris, "Episodic -ee in English: A thematic role constraint on new word formation", Language 74(4), 1998: 695-727.

GLOWCA A. Wayne, "The continuing story of -ola", American Speech 60(2), 1985: 150-156.

MARCHAND Hans, The categories and types of present-day English word-formation, 2nd edition, Munich: Beck, 1969.

OED Online, Oxford University Press, 2012: http://www.oed.com/

RANDLE William, “Payola”, American Speech 36(2), 1961: 104-116.

WRIGHT Joseph, The English Dialect Dictionary, Oxford: Frowde, 1905.

ZIMMER Karl, Affixal negation in English and other languages, Supplement to Word, Monograph 5. New York, 1964

\section{ABSTRACTS}

English is full of words with recurrent sequences of segments which may or may not be morphologically interpretable. In this paper I look at some which fall on either side the cut-off point between morphology and non-morphology, considering what it is that makes something an affix and how we might decide in awkward cases.

INDEX

Keywords: English, affixation, marginal morphology

\section{AUTHOR}

\section{LAURIE BAUER}

Victoria University of Wellington, New Zealand

laurie.bauer@vuw.ac.nz 